\title{
HCI Without Borders?
}

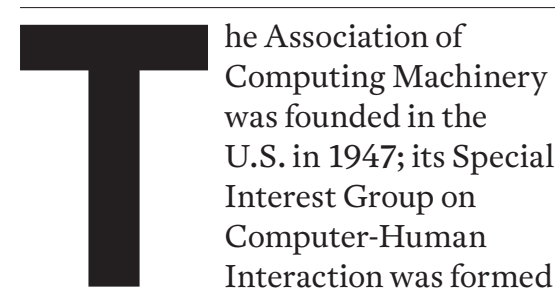

in 1982, also in the U.S. However, for the past generation, the professional field of computing and our discipline of human-computer interaction have become increasingly international, as reflected in our membership and where we do our business.

A large part of "our business" is organizing conferences, and after a decade of American locations, the CHI conference went to Europe. The theme of INTERCHI 1993 was "Bridges Between Worlds," and bridges were indeed built: The CHI conference has returned to Europe about once every four years; many other SIGCHI conferences have been located in Europe; and many Europeans have become involved throughout SIGCHI and across its portfolio of conferences.

But North America and Europe are not the whole world. The previous SIGCHI Executive Committee, led by Gerrit van der Veer and Elizabeth Churchill, worked hard to develop HCI throughout the world, with a special concentration on Eastern
Asia, culminating in the $2015 \mathrm{CHI}$ Conference in Seoul, Korea. CHI 2015 drew more than 2,900 participants, including more than 1,300 from Asia. SIGCHI and the CHI 2015 leadership made significant investments of time and resources both prior to and at the conference to achieve this result, including a number of preparatory workshops, Asian symposia at CHI 2015, and the simultaneous translation of a number of sessions into Korean, Chinese, and Japanese.

The current Executive Committee recognizes the job isn't done: We are committed to building on the foundation laid so far.

We realize there are many different HCI communities across Asia, at differing levels of maturity and with varying needs. We will support the development of HCI research and practice in the region as needed, but our particular focus is integrating Asian HCI research and practice communities into the broad international HCI community, where North Americans and Europeans still dominate.

We are organizing our efforts through the formation of an Asian Development Committee, which consists of representatives from China, India, Japan, South Korea, and Southeast Asia (see http://www.sigchi.
org/people/officers/index_html\#ADC for details). The members of this committee are developing proposals to deepen relationships between their communities and the international HCI community, and to enable fuller participation by Asians in all aspects of the international HCI community. They are also advising the Executive Committee on topics such as locating future SIGCHI-sponsored conferences in Asia, including returning the $\mathrm{CHI}$ conference to the region. The Executive Committee is committed to bringing CHI back to Asia, likely in the early 2020s, although no specific plans are yet in place.

Finally, we should note that North America, Europe, and Asia still are not the whole world. SIGCHI has also worked with HCI communities in Latin America and Africa, and remains committed to helping develop HCI throughout these regions and integrating these communities into the international HCI fold.

We encourage everyone who shares the goal of a true "HCI without borders" to provide their input and ideas to me and to the members of the SIGCHI Executive Committee and Asian Development Committee.

(4) Loren Terveen, President, ACM SIGCHI

$\rightarrow$ sigchi-presidentaacm.org

\section{Our particular focus is integrating Asian $\mathrm{HCl}$ research and practice communities into the broad international $\mathrm{HCl}$ community.}

